Original Research Article

\title{
The comparative effects of Itopride and Levosulpiride orally used in patients suffering from Non-ulcer dyspepsia
}

\author{
Ashish Ranjan ${ }^{1 *}$, Akash Chandra², Deepak Kumar ${ }^{1}$
}

${ }^{1}$ Department of Pharmacology, Sri Krishna Medical College and Hospital, Muzaffarpur, Bihar, India

${ }^{2}$ Department of Pharmacology, Indira Gandhi Institute of Medical Sciences, Patna, Bihar, India

Received: 14 June 2019

Revised: 30 June 2019

Accepted: 16 July 2019

*Correspondence to:

Dr. Akash Chandra,

Email: drakash1984@gmail.com

Copyright: (C) the author(s), publisher and licensee Medip Academy. This is an openaccess article distributed under the terms of the Creative Commons Attribution NonCommercial License, which permits unrestricted noncommercial use, distribution, and reproduction in any medium, provided the original work is properly cited.

\begin{abstract}
Background: Itopride and Levosulpiride both comes under the group of Prokinetic drugs. These drugs are used for the treatment of non-ulcer dyspepsia, heart burn, nausea and vomiting. Both drugs act on dopaminergic D2 receptor as antagonist and increases the concentration of acetylcholine so that gastric peristalsis will be increase and that time pressure at lower oesophageal sphincter will be increase thus gastric motility increases and there will be good gastroduodenal co-ordination.

Method: This study has to conduct on patients with complains of non-ulcer dyspepsia attended Medical outdoor and department of pharmacology of SKMCH Muzaffarpur, Bihar, India. The total 60 patients have to include in the study, which have to randomly divide in two groups. Group A (itopride) comprising of 30 patients and Group B (Levosulpiride) comprising of 30 patients. Patients have to randomly allocate to receive one tablet of itopride hydrochloride, $50 \mathrm{mg}$ three times daily before meal and one tablet Levosulpiride of $75 \mathrm{mg}$ three times daily before meal. Authors have to enroll the patients at the interval of two weeks and continue it upto 3 months.

Results: Study did not found any remarkable change in biochemistry profile. Only QT prolongation changes were found in two patients, but no serious cardiac toxicity was observed with patient receiving Levosulpiride. Neither QT prolongation nor serious cardiac toxicity was observed with itopride hydrochloride therapy.

Conclusions: In present study, efficacy of Itopride was comparable to Levosulpiride in relieving the symptoms of non-ulcer dyspepsia. Both the drugs were clinically and biochemically well tolerated. QT prolongation changes were found in two patients, but no serious cardiac toxicity was observed with patient receiving Levosulpiride. Itopride does not show cardiac toxicity and any changes in ECG.
\end{abstract}

Keywords: Efficacy, Itopride, Levosulpiride, Safety profile, Tolerability

\section{INTRODUCTION}

Dyspepsia is a condition of impaired digestion. ${ }^{1}$ Symptoms include upper abdominal fullness, heartburn, nausea, belching or upper abdominal pain. ${ }^{2}$ People may also experience feeling full earlier than expected when eating. ${ }^{3}$ Dyspepsia is a common problem and is frequently caused by gastroesophageal reflux disease (GERD) or gastritis. ${ }^{4}$ Many medications cause dyspepsia, including aspirin, metronidazole, macrolides, metformin, Alphaglucosidase inhibitor, amylin analogs, GLP-1 receptor antagonists, angiotensin converting enzyme (ACE) inhibitors, Angiotensin II receptor antagonist, niacin, fibrates, neuropsychiatric medications like donepezil, rivastigmine, SSRIs like fluoxetine, sertraline, serotoninnorepinephrine-reuptake inhibitors like venlafaxine, duloxetine, Parkinson drugs like Dopamine agonist, (MAO)-B inhibitors, corticosteroids, estrogens, digoxin, iron, and opioids. ${ }^{5}$ Itopride is a prokinetic benzamide derivative. It inhibits dopamine and acetylcholine esterase enzyme and have a gastrokinetic effect. ${ }^{6}$ Itopride is indicated for the treatment of functional dyspepsia and 
other gastrointestinal conditions. ${ }^{7}$ The most common sideeffects of itopride include mild to moderate abdominal pain and diarrhoea. ${ }^{8}$

Some other side effects that may occur include rash, giddiness, exhaustion, back or chest pain, increased salivation, constipation, headache, sleeping disorders, dizziness, galactorrhea, and gynecomastia.

Levosulpiride is a substituted benzamide antipsychotic, reported to be a selective antagonist of dopamine D2 receptor activity on both central and peripheral levels. It is an atypical neuroleptic and a prokinetic agent.

Levosulpiride is used in the treatment of psychoses, negative symptoms of schizophrenia, anxiety disorders, dysthymia, vertigo, dyspepsia, irritable bowel syndrome and premature ejaculation.Side effects include amenorrhea, gynecomastia, galactorrhea, changes in libido, and neuroleptic malignant syndrome.

\section{METHODS}

This study was conducted on patients with complains of non-ulcer dyspepsia attended Medical outdoor and department of pharmacology of SKMCH Muzaffarpur, Bihar, India.

\section{Inclusion criteria}

- Patients presenting with complaints of non-ulcer dyspepsia like epigastric distention or pain, nausea, heartburn, for at least 12 weeks

- $\quad$ Patients age 18-60 yrs (male/female)

- Informed consent.

\section{Exclusion criteria}

- Patients with endoscopic evidence of ulcer disease and severe esophagitis

- History of chronic intake of NSAIDS, Anticoagulants and acid suppressants

- Pregnant and lactating women

- Patients suffering from any systemic disease

- Patients not below than 18 years and above than 65 years (male/female).

\section{Procedure}

Patients were randomly allocated to receive one tablet of itopride hydrochloride, $50 \mathrm{mg}$ three times daily before meal and one tablet of Levosulpiride, $75 \mathrm{mg}$ three times a day before meal for two weeks and continue it up to three months.

Concomitant medication with any other prokinetic drugs antacids enzyme preparations, H2-blockers, or proton pump inhibitor were not permitted during the study period.
They were advised to avoid alcohol and smoking during the study period.

\section{Outcome and measures}

Patients symptoms were graded on a 4-point scale (0 to 3 ).

\section{Grading of symptoms}

- No symptoms

- $\quad$ Mild symptoms

- Moderate symptoms

- $\quad$ Severe symptoms.

Symptoms were re-evaluated two weeks later. Following treatment, relief of symptom was assessed at the end of 2 weeks on a 5-points scale (1 to 5).

Grading of response (Based on subjective perception)

- Marked or complete relief

- Moderate relief

- $\quad$ Slight relief

- No relief

- Worsening of symptoms.

A 12 lead ECG was done on each patient at the screening visit to exclude QT prolongation, and at the end of 2 weeks to detect effect of Itopride and Levosulpiride on QT prolongation. Biochemical investigation like complete hemogram, blood urea, serum creatinine, liver function test was done at the screening visit and at the end of treatment. Clinical adverse events, if any were recorded at the end of week 2 , along with their nature, intensity, action taken and outcome.

\section{Statically analysis}

The total 60 patients were included in the study, which was randomly in two groups. Group A (Itopride ) comprising of 30 patients and Group B (Levosulpiride) comprising of 30 patients. Data are presented as mean \pm SD. Score for the symptoms are presented as median (range). Statistical analysis was done using two-tailed paired t-test, Wilcoxon matched paired rank sum test, Mann Whitney test and Chisquare test for as applicable.

\section{RESULTS}

In present study, authors included total 60 cases divided into two groups. Group A (Itopride hydrochloride) included 30 patients with 17 male and 13 females. Male to female ratio was 1.30:1, mean age in group $\mathrm{A}$ was $35.36 \pm 9.79$, in Group B (Levosulpiride) total 30 patients were included with 16 male and 14 females. Male to female ratio was $1.14: 1$, mean age in group B was $35.1 \pm 9.65$. 
Symptomatic relief was moderate to complete in $27(90 \%)$ patients on itopride and in $25(83.33 \%)$ patients on Levosulpiride $\left(\mathrm{X}^{2}=5.9624, \mathrm{DF}=1, \mathrm{p}\right.$ value $\left.=0.0146\right)$. The difference was statistically significant.

QT-interval in any case was not prolonged with treatment of itopride hydrochloride. In two cases showed prolongation of QT-interval with treatment of
Levosulpiride but serious cardiac toxicity like Torsades de pointes was not observed. Therapy with both drugs did not produce any abnormalities in serum biochemistry profile at the end of 2-week therapy. Two adverse effects were reported by one patient in each group, headache by a patient receiving itopride and diarrhoea by one patient receiving Levosulpiride. Both were mild and subside without interfering with continuation of the treatment.

Table 1: Age and sex distribution in cases of non-ulcer dyspepsia.

\begin{tabular}{|llllllll|}
\hline Group A (Itopride) & \multicolumn{7}{c|}{ Group B (Levosulpiride) } \\
\hline Age in years & Male & Female & Total & Age in years & Male & Female & Total \\
\hline $10-20$ & 1 & 1 & 2 & $10-20$ & 1 & 1 & 2 \\
\hline $21-30$ & 5 & 3 & 8 & $21-30$ & 6 & 4 & 10 \\
\hline $31-40$ & 5 & 6 & 11 & $31-40$ & 7 & 5 & 12 \\
\hline $41-50$ & 4 & 2 & 6 & $41-51$ & 1 & 2 & 3 \\
\hline $51-60$ & 2 & 1 & 3 & $51-60$ & 1 & 2 & 30 \\
\hline Total (N) & & & 30 & Total (N) & & \\
\hline
\end{tabular}

Table 2: Response of treatment in patients with non-ulcer dyspepsia.

\begin{tabular}{|lllllll|}
\hline \multirow{2}{*}{ Response } & \multicolumn{2}{l}{ Group A (Itopride) } & \multicolumn{4}{l|}{ Group B (Levosulpiride) } \\
& No. of patients & & \multicolumn{2}{l|}{ No. of patients } \\
& Male & Female & Total & Male & Female & Total \\
\hline Marked or complete relief & 10 & 7 & 17 & 7 & 6 & 13 \\
\hline Moderate relief & 6 & 4 & 10 & 8 & 1 & 9 \\
\hline Slight relief & 1 & 1 & 2 & 2 & 3 & 5 \\
\hline No relief & 0 & 1 & 1 & 1 & 2 & 3 \\
\hline Worsening of symptoms & 0 & 0 & 0 & 0 & 0 & 0 \\
\hline Total (N) & & & 30 & Total (N) & 30 \\
\hline
\end{tabular}

Table 3: Effect of therapy on serum biochemistry and QT interval.

\begin{tabular}{|c|c|c|c|c|}
\hline Parameter & $\begin{array}{l}\text { Itopride } \\
\text { Group Pre-R }\end{array}$ & $\begin{array}{l}\text { Itopride } \\
\text { Group Post-R }\end{array}$ & $\begin{array}{l}\text { Levosulpiride group } \\
\text { Pre- } \mathbf{R}_{\mathbf{x}}\end{array}$ & $\begin{array}{l}\text { Levosulpiride group } \\
\text { Post-R }\end{array}$ \\
\hline $\mathrm{Hb}(\mathrm{mg} / \mathrm{dl})$ & $12.2 \pm 1.76$ & $12.0 \pm 2.05$ & $11.55 \pm 2.05$ & $11.49 \pm 1.98$ \\
\hline WBC-TC (/cumm) & $8885 \pm 2414$ & $8600 \pm 2158$ & $8100 \pm 2827$ & $8500 \pm 2479$ \\
\hline $\mathrm{BUN}(\mathrm{mg} / \mathrm{ml})$ & $8.1 \pm 1.45$ & $8.16 \pm 1.57$ & $8.2 \pm 1.51$ & $9.07 \pm 2.25$ \\
\hline Creatinine & $0.8 \pm 0.1$ & $0.81 \pm 0.11$ & $0.79 \pm 0.11$ & $0.79 \pm 0.11$ \\
\hline AST (units/L) & $27.62 \pm 9.17$ & $27.25 \pm 0.16$ & $25.85 \pm 8.19$ & $23.74 \pm 6.93$ \\
\hline ALT (units/L) & $30.11 \pm 9.02$ & $29.92 \pm 0.16$ & $30.67 \pm 8.19$ & $29.11 \pm 6.93$ \\
\hline Y-GT (units) & $30.14 \pm 12.5$ & $33.21 \pm 10.2$ & $24.66 \pm 18.9$ & $26.0 \pm 19.6$ \\
\hline Alk. Phos (units/ml) & $133 \pm 23.5$ & $143 \pm 25.5$ & $134.8 \pm 28.2$ & $129.11 \pm 32.8$ \\
\hline Bilirubin (mg/dl) & $0.97 \pm 0.3$ & $0.96 \pm 0.2$ & $0.94 \pm 0.1$ & $0.89 \pm 0.1$ \\
\hline Total cholesterol (mg/dl) & $166.1 \pm 46.6$ & $163.4 \pm 33.9$ & $168.6 \pm 32.8$ & $160.8 \pm 27.9$ \\
\hline FBS $(\mathrm{mg} / \mathrm{dl})$ & $81.8 \pm 18.1$ & $85.96 \pm 8.3$ & $82.1 \pm 9.2$ & $81.8 \pm 8.2$ \\
\hline QT-Interval & $0.34 \pm 0.044$ & $0.34 \pm 0.042$ & $0.40 \pm 0.055$ & $0.40 \pm 0.060$ \\
\hline
\end{tabular}

Table 4: Adverse effect of therapy.

\begin{tabular}{|lllll|}
\hline Adverse Effect & Group A (Itopride) & $\mathbf{N}=\mathbf{3 0}$ & \multicolumn{2}{l|}{ Group B (Levosulpiride) $\mathbf{N}=\mathbf{3 0}$} \\
\hline & No. of case & $\mathbf{\%}$ & No. of cases & $\mathbf{\%}$ \\
\hline Headache & 1 & 3.34 & 0 & 0 \\
\hline Diarrhoea & 0 & 0 & 1 & 3.34 \\
\hline
\end{tabular}




\section{DISCUSSION}

Authors took a total of 60 patients which are divided into two groups after randomization, Group A (Itopride) $n=30$ and Group B (Levosulpiride) n=30. Patients in both groups are similar in term of age, sex and weight. In this study, the mean age of patients in group A was (35.36 \pm 9.79$)$ and in Group B was (35.1 \pm 9.65 .There were 17 male, 13 female in Group A (M:F;1.30:1) and 16 male, 14 female in Group B (M:F;1.14:1), which are almost comparable. The overall male to female ratio was 1.22:1 Their median age was 35 years, median weight $50 \mathrm{~kg}$ and median duration of complaints, 12 weeks. The patients were matched for age and body weight. Four patients in Itopride group and two in the Levosulpiride group had a history of smoking. Six patients in the Itopride group and two in Levosulpiride group had history of intake of ulcerogenic drugs for some periods. Dietary history revealed that diet was spicy in 14 patients in the Itopride group and in 19 patients in Levosulpiride group. Only one patient in Itopride group had a history of intake of very spicy diet. The remaining patients in both groups consumed a mild non-spicy diet. At baseline, the median scores for symptoms were mild to moderate in both the groups. Following therapy, the median scores for the individual symptoms declined significantly in both the groups. Symptomatic relief was moderate to complete in $27(90 \%)$ patients on Itopride and in $19(83.33 \%)$ patients on Levosulpiride $(\mathrm{P}=0.0146)$. The difference was statically significant. One patient in each group reported two adverse events, headache by a patient receiving Itopride and diarrhoea by one patient receiving Levosulpiride. Both were mild and subside without interfering with continuation of the treatment. Clinical tolerability was good to excellent in all the patients. Four cases in the study showed the decrease in leucocyte count. Leucopenia was mild and need not to be discontinuation of treatment. Effect on liver function enzymes like serum bilirubin, alkaline phosphatase, alanine aminotransferase, aspartate aminotransferase were variable. There was no significant effect on liver enzymes and no need to be discontinuation of treatment. All effects were subsided after completion of treatment. Itopride hydrochloride is a D2-receptor blocker. ${ }^{9}$ During study no extrapyramidal symptoms were observed. Even in Levosulpiride group has the potential to cause extrapyramidal sympyoms, but during study no cases were observed with extrapyramidal symptoms. QT-interval in any case was not prolonged with treatment of itopride hydrochloride. ${ }^{8}$ In two cases showed prolongation of QT-interval with treatment of Levosulpiride but serious cardiac toxicity like Torsades de pointes was not observed. Therapy with both drugs did not produce any abnormalities in serum biochemistry profile at the end of 2-week therapy. Therapy with both drugs was well tolerated and two patients showed prolongation of QT interval with treatment of Levosulpiride but serious cardiac side effect like Torsades de pointes was not observed.

\section{CONCLUSION}

In present study, efficacy of Itopride was comparable to Levosulpiride in relieving the symptoms of non-ulcer dyspepsia. Both the drugs were clinically and biochemically well tolerated. Only QT prolongation changes were found in two patients, but no serious cardiac toxicity was observed with patient receiving Levosulpiride. Neither QT prolongation nor serious cardiac toxicity was observed with itopride hydrochloride therapy.

Funding: No funding sources

Conflict of interest: None declared

Ethical approval: The study was approved by the Institutional Ethics Committee

\section{REFERENCES}

1. Dyspepsia at Dorland's Medical Dictionary.

2. Duvnjak, edited by Marko. Dyspepsia in clinical practice (1. Aufl. Ed.). New York: Springer; 2011:2.

3. Talley NJ, Vakil N. Guidelines for the management of dyspepsia. Am J Gastroenterol. 2005;100(10):232437.

4. Zajac P, Holbrook A, Super ME, Vogt M. An overview: current clinical guidelines for the evaluation, diagnosis, treatment, and management of dyspepsia. Osteopathic Fam Physician. 2013;5(2):7985.

5. Ford AC, Moayyedi P. Dysepsia. BMJ. 2013;347:f 5059.

6. Iwanaga Y, Miyashita N, Saito T, Morikawa K, Itoh Z. Gastroprokinetic effect of a new benzamide derivative itopride and its action mechanisms in conscious dogs. Japanese J Pharmacol. 1996;71(2):129-37.

7. Holtmann G, Talley NJ, Liebregts T, Adam B, Parow C. A placebo-controlled trial of itopride in functional dyspepsia. 2006;354(8):832-40.

8. Huang X, Lv B, Zhang S, Fan YH, Meng LN. Itopride therapy for functional dyspepsia: a metaanalysis. World J Gastroenterol. 2012;18(48):7371-7.

9. Chey, William Y. Irritable Bowel Syndrome, An Issue of Gastroenterology Clinics-E-Book. Elsevier Health Sciences; 2011.

Cite this article as: Ranjan a, Chandra A, Kumar D. To study the comparative effects of Itopride and Levosulpiride orally used in patients suffering from non-ulcer dyspepsia. Int J Basic Clin Pharmacol 2019;8:1915-8. 